\title{
Me and My Avatar: Player-Character as Fictional Proxy
}

\author{
Matthew Carlson and Logan Taylor*
}

Players of videogames describe their gameplay in the first person, e.g. "I took cover behind a barricade.” Such descriptions of gameplay experiences are commonplace, but also puzzling because players are actually just pushing buttons, not engaging in the activities described by their first-person reports. According to a view defended by Robson and Meskin (2016), which we call the fictional identity view, this puzzle is solved by claiming that the player is fictionally identical with the player character. Hence, on this view, if the player-character fictionally performs an action then, fictionally, the player performs that action. However, we argue that the fictional identity view does not make sense of players' gameplay experiences and their descriptions of them. We develop an alternative account of the relationship between the player and player-character on which the player-character serves as the player's fictional proxy, and argue that this account makes better sense of the nature of videogames as interactive fictions.

Keywords: avatar, player-character, fictional identity, imagination, fictional proxy, interactive fiction, responsibility.

"Did you just shoot that guy?" If you are playing a videogame, the natural answer to this question might be “yes.” In reporting on one's activities while playing Spec Ops: The Line (Yager Development, 2012), for example, one might say, "I shot an enemy soldier with a rifle." ${ }^{1}$ Of course, this is not literally true-I was safely seated on my couch, not battling rogue American soldiers in the ruins of Dubai-but the point here is simply that such first-person reports are perfectly natural; this is the language with which gamers describe their gameplay. We think that the naturalness of such first-person reports on in-game activity reveals something about the unique way in which videogames are interactive, and consequently we propose to take this way of talking at

We would like to thank Michael Abbott, and anonymous reviewers for this journal, for comments on earlier versions of this paper that led to substantial improvements. We presented earlier versions of this work at the Fall 2016 Meeting of the Indiana Philosophical Association, and in an introductory class on videogames and philosophy at Wabash College. We are grateful to audiences on both occasions for helpful comments and suggestions. We are also grateful to Wabash College for funding the initial research on this project in the Summer of 2016.

1 Nothing in our argument turns on this particular choice of game. Such first-person reports of gameplay are common to all videogames with a player-character (and perhaps to all videogames, but to keep our topic manageable, we focus here on games with a player-character). 
face value. ${ }^{2}$ The task of this paper is to make some progress in understanding what these first-person reports of gameplay experiences reveal about the status of videogames as interactive fictions.

In this discussion, we will mostly focus our attention on games with playercharacters (hereafter "PCs"). ${ }^{3}$ For now, let's just say that a PC in a videogame is a character in that game's fiction that is specially linked to the player's control. This rough-and-ready characterization will, we hope, serve to delineate the subject matter, but will be subject to significant clarification below. Moreover, since it will serve as an important example throughout this paper, a brief bit of background on Spec Ops: The Line is in order here. Spec Ops is a "military shooter" videogame whose story is loosely based on Heart of Darkness (Conrad 1899). The story concerns an elite American soldier, Captain Walker (the PC), who must lead a small force of American troops on a mission to find the rogue Colonel Konrad. Over the course of the game, Captain Walker must commit numerous atrocities, including killing civilian refugees in disaster-stricken Dubai, in order to progress. Sadly, such violence is commonplace in games of the "military shooter" genre. What makes Spec Ops especially noteworthy is the way that it draws the player's attention to the fact that the player is causing the horrific in-game violence (Payne 2014). We will have more to say about the import of this feature of Spec Ops in our discussion below.

\section{Videogames as Interactive Fictions}

It is not literally true that I shot an enemy soldier with a rifle. It seems more accurate to say that the PC, Captain Walker, in my playing of Spec Ops, did those things. ${ }^{4}$ This is still not literally true, but at least the problem is now a familiar one: Captain Walker is a fictional character and thus did not actually do any of those things. To resolve this issue, we will employ the mechanics of Kendall Walton's (1990) view. ${ }^{5}$ Very briefly, Walton holds that when we engage with works of fiction, we are playing games of make-believe. What is depicted in the fiction serves as a "prop" to aid our imaginations, and what makes a claim like "Walker took cover behind a barricade" true in the fiction is that, in the context of our engagement with the fiction, there is a mandate for us to imagine that Walker took cover behind a barricade. Thus, according to Walton, if $p$ is fictionally true (in what Walton calls the "work world" of the fiction), then in engaging with the fiction

\footnotetext{
Velleman (2008), and Robson and Meskin (2016), for example, also take this methodological approach. Some authors prefer 'avatar' to 'player-character'. We prefer 'player-character', for reasons that Grant Tavinor articulates (Tavinor 2009, 70), but the terms can be used interchangeably in the context of our discussion here. To avoid unnecessary complications, we focus on individual playings of a game, in a way analogous to that in which discussions of theater or music might focus on individual performances of a work. Compare Robson and Meskin (hereafter R\&M, 2016, 167).

None of our main points depend on the particulars of Walton's view. We employ it here because it readily applies to videogame fictions, and is already employed in much of the extant literature on such fictions (e.g. Tavinor 2009, R\&M 2016).
} 
one is mandated to imagine that $p$. On Walton's view, for example, it is fictionally true in the work world of Spec Ops that Captain Walker took cover behind a barricade because, when engaging with the game, we are to imagine that Captain Walker took cover behind a barricade.

This is fine, so far as at it goes, but it as yet does nothing to explain how it could be correct to say that $I$ did those things. This special problem arises due to the fact that videogames are interactive fictions. When we say that a work is interactive, we have in mind Lopes' account, according to which "a work of art is interactive just in case it prescribes that the actions of its users help generate its display" (Lopes 2010, 36). The key idea is that the actions of appreciators of interactive artworks help to determine their content, and moreover, that these actions of the appreciators are prescribed by the artwork. It is part of the content of my particular playing of Spec Ops that Captain Walker is displayed as taking cover behind a barricade. Moreover, this particular content is displayed only because of something that I-the player-did, namely, manipulating the controller in a certain way. And, my engagement with the work in this way (altering its display by manipulating the controller) is prescribed by the work. It's a game; you're supposed to play it.

Employing this understanding of "interactive", we can explain why videogames are interactive fictions. According to Grant Tavinor (2009, 55-57), videogames are interactive fictions because the player interacts with the physical controls of the game and thereby influences what is true in the game's fiction. Thus, on this model,

(i) really, I pressed the $\mathrm{X}$ button on my gamepad, ${ }^{6}$

and as a result,

(ii) fictionally, Captain Walker took cover behind a barricade.

Moreover, (ii) is counterfactually dependent on (i): Had not I not pressed X on my gamepad, it would not have been fictional that Captain Walker took cover behind a barricade. Thus, videogames are interactive fictions in the sense that what's true in the fiction depends in part on the input of the player.

This is progress, but it still does not explain why first-person reports on in-game activity are appropriate. The problem, in other words, is to explain how we can get from (i) and (ii) to

(iii) fictionally, I took cover behind a barricade.

" $\mathrm{X}$ " is the lower action button on the Playstation controller. Obviously, nothing in our argument turns on this choice of example. It is sufficient for our purposes that the player performs some action that provides input to the game. 
To make progress in explaining why reports like (iii) are appropriate, we turn in the next section to examining an account recently defended by Jon Robson and Aaron Meskin.

\section{The Fictional Identity View}

Robson and Meskin argue that videogames are part of a wider class of works that they call "Self-Involving Interactive Fictions" (SIIFs), which are "fictions that, in virtue of their interactive nature, are about those who consume them"7 (R\&M 2016, 165). Other members of this class of works include tabletop role-playing games like Dungeons \& Dragons (Tactical Studies Rules, 1974) and books like those in the Choose Your Own Adventure (Bantam Books, 1979-1998) series. Videogames are SIIFs, they claim, because when the player of a videogame makes gameplay decisions, "these decisions not only make certain things fictional concerning her avatar but also-given that her avatar is fictionally her-make many of the same things fictionally true about her" (R\&M 2016, 168, emphasis added). Thus, according to R\&M, videogames are SIIFs because players of videogames are fictionally identical with the PCs of those respective games. In a response to Stephanie Patridge, R\&M clarify this idea, writing that "[i]f all that is meant by saying that the player identifies with her avatar is that she is prescribed to imagine that the avatar is her, ... then this is indeed something which we are committed to accepting” (R\&M 2017, 186, emphasis added). On R\&M’s account, the player is prescribed to imagine that she is the avatar (PC). In Walton's framework, which R\&M accept, this implies that it is true in the fiction that the player is the PC. Thus, we take it that R\&M are committed to accepting the thesis that we call:

Fictional Identity (FI): Fictionally, the player is the PC. ${ }^{8}$

Moreover, FI plays a clear role in R\&M’s explanation of why videogames are SIIFs, and why the first-person reports on videogame activities seem so natural. Applying FI we can reason as follows.

(i) Really, I pressed the $\mathrm{X}$ button on my gamepad,

and as a result,

(ii) fictionally, Captain Walker took cover behind a barricade.

As above, the relationship between (i) and (ii) shows that Spec Ops is an interactive fiction. Further, FI helps to clarify the sense in which Spec Ops is “self-involving” since it implies that

R\&M allow that some videogames, e.g. computer chess, might not have sufficiently robust fictions to count as SIIFs. But all of the games we consider here should be clear examples of SIIFs, as R\&M understand them.

8 FI also appears to be accepted by others in the literature, though we lack space to discuss the views of other authors who endorse it here. See, for example, Tavinor $(2009,70)$ and Juul $(2005,161)$. 
fictionally, the player is Captain Walker.

Consequently, we can simply substitute identicals and conclude that

(iii) fictionally, I took cover behind a barricade.

(iii) is about the player (the referent of "I" in this context), and moreover, it is about the player in virtue of Spec Ops' interactive character; it is about the player only because of the relationship between (i) and (ii). Thus, applying R\&M's view, FI explains why Spec Ops is a SIIF, and thus why claims like (iii) are appropriate.

For our purposes here, it is important to emphasize two features of R\&M's argument. First, they argue that videogames are self-involving - in the sense that the truths of the work world of a videogame fiction will include truths like (iii), which are about the player-because in the videogame's fiction, the player is the PC. In other words, on R\&M's account, FI is the reason why videogames are "self-involving", and thus FI is the main reason why videogames are SIIFs. Second, R\&M's major support for the claim that videogames are SIIFs is that, if videogames are SIIFs, then we can make sense of first person reports like (iii). As R\&M put it, a significant advantage of the view that videogames are SIIFs is that it "preserves the standard way in which players think and talk about their interactions with video games” (R\&M 2016, 168).

Below, we will present two problems which, we believe, show that FI does not preserve the standard way in which players think and talk about their interactions with video games. Thus, since the thesis that videogames are SIIFs depends on FI, it follows that the thesis that videogames are SIIFs does not preserve the standard way in which players think and talk about their interactions with videogames. Since this was the primary support for the SIIF thesis, we conclude that R\&M have failed to show that videogames are SIIFs. However, we agree with R\&M that videogames, at least videogames with player-characters, are SIIFs. ${ }^{9}$ To make this case, in the final section we articulate an alternative to FI-we call it the fictional proxy view (FP) — and show how FP avoids the problems that we raise for FI. We conclude that the fictional proxy account shows that videogames are SIIFs, as R\&M contend. Nevertheless, the fictional proxy account also shows, contrary to R\&M’s view, that the way in which videogames are interactive makes them importantly different from other kinds of SIIFs.

\section{The Asymmetry Problem}

As we explained in the previous section, FI is the thesis that, fictionally, the player is the PC. In Walton's framework, which R\&M accept, this implies that the player is to

\footnotetext{
In the final section of this paper, we suggest how our account may be generalized to show that all videogames are SIIFs. But our main focus in the paper is on videogames with player-characters. In the interest of avoiding unnecessary prolixity, we sometimes leave this qualification unstated.
} 
imagine that she is the PC. Thus, FI is quite similar to a theory of identification with fictional characters defended by Berys Gaut (Gaut 1999). ${ }^{10}$ As Gaut notes, the idea that a viewer imagines that she is a character is subject to a basic problem articulated by Richard Wollheim (Wollheim 1973, 80). Wollheim points out that identity is symmetrical. Applying Wollheim's point about the symmetry of identity, it follows that the player's imagining that she is Walker is equivalent to Walker's imagining that he is the player. But these are clearly quite different acts of imagining, at the very least because one is real and one is fictional. In order to avoid this problem, Gaut defends the view that, in imaginatively identifying with a character, we do not imagine being them, but rather, we imagine being in their situation, "where the idea of her situation encompasses every property she possesses, including all her physical and psychological traits..."11 (Gaut 1999, 203). Thus, according to Gaut, "what I do in imaginatively identifying myself with [a fictional character] is imagining being in his situation, doing what he does, feeling what he does, and so on" (Gaut 1999, 203). Consequently, to avoid Wollheim's problem, we might follow Gaut and interpret FI as implying only that the player is to imagine that she is in the PC's situation.

But even on this interpretation, FI faces an asymmetry problem articulated by Noël Carroll (Carroll 1990, 2001). Gaut is explicit in claiming that, when we imagine ourselves to be in a character's situation, we imagine ourselves to have all of the character's physical and psychological traits. Thus, on this view, when I identify myself with a fictional character, I imagine myself to feel as that character feels. But, as Carroll points out in his discussion of imaginative identification, we often do not imagine ourselves to feel as fictional characters feel. In fact, it is much more typical that we respond to the emotional states of characters - even those with whom we identify — with emotions that differ from those of the characters (Carroll 1990, 91). And this problem for theories of fictional identification applies with equal weight to FI. According to FI, the player is to imagine that she is the PC, or if we accept Gaut's modification, that she is in the PC's situation. Consequently, if FI is true, the following inference should go through.

(ii*) fictionally, Captain Walker is angry at the refugees in Dubai.

Therefore, since it is fictional that I am Walker (FI),

(iii*) fictionally, I am angry at the refugees in Dubai. $^{12}$

10 Gaut is primarily concerned with identification with characters in films. Nevertheless, his account applies readily to videogames as well. We are grateful to an anonymous reviewer for this journal for bringing Gaut's work on this issue to our attention.

11 Wollheim himself develops a similar thought. See (Wollheim 1973, 81-82).

12 We start with (ii*) in numbering here to display the parallel in structure to the reasoning presented at the end of the previous section. 
By this point in the game, Walker has become deeply delusional, and is convinced that the refugees in Dubai, whom he originally set out to save, are in fact his enemies. In these scenes, players are not likely to share Walker's anger, but instead be disturbed by the fact that he is so angry. There is thus an asymmetry between the Walker's emotions and the player's. And we think this case is not unusual. Typically, gamers do not imaginatively take on the emotional states that their avatars have in the fiction. This is not to say that gamers never imagine themselves to feel as their avatars feel, but only that they often don't. Thus, FI is also subject to Carroll's asymmetry problem: The problem is just that, contrary to what FI predicts, players do not usually imagine themselves to be in the situations, in Gaut's sense, of their PCs.

In his recent criticism of R\&M, Aaron Suduiko (2018) articulates an important special case of the asymmetry problem. Suduiko identifies four data concerning videogame narratives which, he claims, any account of storytelling in videogames ought to account for. Of particular interest here are what Suduiko calls the explanatory and epistemic data. ${ }^{13}$ The explanatory datum is that, in many cases, the PC's actions cannot be explained by appealing only to the PC's mental states. To take Suduiko's example, in a particular playing of a game, the PC might avoid going around a certain corner, but this action is not explicable in terms of any mental states of the PC. Instead, the PC avoids the corner because the player knows that a dangerous monster lurks behind it (Suduiko 2018, 12). The epistemic datum is closely related to this. This datum is that the PC's beliefs and other attitudes about the game's fiction are often different from those of the player and that this difference can be a source of narrative depth. As Suduiko points out, this is particularly important for understanding games like Spec Ops, in which the PC's interpretations of the game's events are revealed to be radically unreliable (Suduiko 2018, 15). As Suduiko puts it, "avatars are characters with fictional histories and mental lives, and the fact that a player can control some of the avatar's decisions does not entail that the player has access to these histories and mental lives" (Suduiko 2018, 10). The problem raised by these data is a special case of the asymmetry problem because, as Suduiko points out, the PC's imagined epistemic state is different from the player's epistemic state. As in Suduiko's example, it may be correct to say that

13 Suduiko calls the other data that he identifies the exploratory and variability data. The exploratory datum is that, in playing a videogame, the player often explores the "possibility structure" of the game by replaying certain sections and making different choices to see what happens (Suduiko 2018, 8). We think that this datum is adequately accounted for by bearing in mind that we (and R\&M) are focusing on a single playing of a game (see footnote 4). In a single playing of a game, it is not possible to explore a game's possibility structure in this way, since each replaying of a section is a new playing of a game, except perhaps in very unusual cases of games like The Stanley Parable (Galactic Cafe, 2013), which are in some sense about their own possibility structure. Thus, the exploratory datum is not a datum about single playings of games, which we and R\&M focus on. The variability datum is that many videogames do not feature a single PC with whom the player might be identified (Suduiko 2018, 7). We agree with Suduiko that this datum poses a serious problem for R\&M's account, especially as it concerns games with no PC, or with multiple PCs that the player controls simultaneously. We will have more to say about how our own account might handle this datum in the final section of this paper. 
"I know there is a monster around the corner" even in cases in which it is not plausible that the PC knows that there is a monster around the corner. But, if the player knows that there is a monster around the corner, and as FI has it, the player fictionally is the PC, then fictionally, the PC must also know that there is a monster around the corner. As Suduiko rightly notes, this is implausible (Suduiko 2018, 6).

However, Suduiko's positive account is also subject to the asymmetry problem. Suduiko proposes to account for the data that he articulates by positing a "fictional player" which he characterizes as "an abstract fictional entity" that operates on the possibility structure of a game's fiction, thereby making it the case that certain possible events within that structure are actual in the fiction of that particular playing of the game (Suduiko 2018, 10). The difficulty for this account is that now the relationship between the real player and the fictional player must be explained. To see this, consider Suduiko's discussion of how his account handles the explanatory datum. The challenge is to give an explanatory answer to the following question: "Why did the PC avoid that corner?" Suduiko's answer is: "The fictional player knew that there is a powerful monster behind that corner, and therefore made it the case that [the PC] avoided it" (Suduiko 2018, 12). The fictional player's knowledge and agency is here supposed to explain the PC's fictional action of avoiding the corner. But videogames (at least the games under consideration here) are works of interactive fiction. Thus, it must be the case that, as Suduiko puts it, "the person engaging one such narrative has some degree of control over which subsequent narrative is brought about...” (Suduiko 2018, 4, emphasis added). Thus, the correct explanation of the PC's behavior cannot simply appeal to the fictional player's agency; since games are interactive, the correct explanation of the PC's behavior must appeal at some point to actions taken by the real player.

How, then, do we explain the relationship between the real player and the fictional player, on Suduiko's account? The relationship cannot be fictional identity since Suduiko acknowledges that it is possible for the player to have knowledge that the fictional player lacks. Suduiko's example is that the real player might come to know information about a game's fiction by reading a strategy guide, but since the strategy guide is outside of the game's fiction, the fictional player would not have this knowledge. As Suduiko puts it: "The fictional player did not read the guide: the real player did" (Suduiko 2018, 13, emphasis in original). That is, the player has knowledge which the fictional player lacks. Consequently, the fictional player cannot be fictionally identical to the player, for the same reason that the PC cannot be fictionally identical to 
the player. Thus, both R\&M's fictional identity account and Suduiko's fictional player account fall prey to the asymmetry problem. ${ }^{14}$

At this point, it may be worthwhile to reflect briefly on why the asymmetry problem arises for these accounts. According to $\mathrm{R} \& \mathrm{M}$, the player "imagines herself to be identical with a particular fictional character" but they provide examples like "we imagine that we are Chris Redfield shooting zombies in Resident Evil 5 (Capcom, 2009) or the unnamed marine battling the demonic hordes of Doom (id Software, 2016)" (R\&M 2016, 169, emphasis added). The disconnect between the general claim that the player is fictionally identical with a character in the game's fiction-the thesis FI-and the specific examples that R\&M choose here is revealing. We may well imagine that we are shooting, battling, or doing any of the other actions that videogames represent so well, but we don't really imagine that we are identical with the on-screen character who is performing those actions. ${ }^{15}$ The asymmetry problem arises for the accounts we have considered because these accounts attempt to explain the relationship between the player and the PC's actions by positing a general relationship of identification between the player and a fictional element in the game. The asymmetry problem thus suggests that the player is not to be fictionally identified with the PC, full stop, but rather to be identified, in a sense yet to be explained, only with the PC's actions. Notice that if this is correct, it would explain why it is fictionally true that I took cover behind a barricadebecause this describes the PC's actions - and why it is fictionally false that I am angry at the refugees in Dubai-it simply describes the PC's mental states.

This suggests that we might solve the asymmetry problem by considering, as Gaut proposes, that fictional identification is aspectual. According to this view, we don't completely identify with characters, but instead only identify with them in some respects. And, which respects these are can vary from situation to situation. We can, for example, identify with a character perceptually, by imagining "seeing from his point of view," without identifying with him affectively; that is, without imaging "feeling what he feels” (Gaut 1999, 205). This suggests that we could re-interpret FI so as to avoid the asymmetry problem. In claiming that, fictionally, the player is the PC, perhaps all that is meant is that the player is to imaginatively identify only with one aspect of the PC; namely, the PC's actions. This is an intriguing suggestion, but we think it will not work.

14 We will have more to say about this in the final section of this paper. In particular, we think that the fictional proxy view we develop there might be extended to explain the relationship between the player and Suduiko's fictional player.

15 In her recent criticism of R\&M's view, Stephanie Patridge seems to be picking up on a similar point. She concedes that "it is in some thin sense fictionally true (or true fictionally, as the case may be) that I hurl a fireball at my opponent's hero or that I land on Park Place and so have to pay money to my opponent or that I am wandering around Kaitlin's house.” But, she continues, "none of these descriptions involves imaginative identification with an avatar...” (Patridge 2017, 183, emphasis added). 
To see why, we must consider a related problem for FI that concerns the player's responsibility for in-game activities.

\section{The Responsibility Problem}

R\&M claim that a virtue of their account is that it helps us to explain why videogames appear to pose special moral problems. For example, many players are made uncomfortable by the "By the Book" mission in Grand Theft Auto V (Rockstar Games, 2013) in which Trevor (the PC at this point in the game) must torture an NPC in order to progress. ${ }^{16}$ According to R\&M, the appearance of a special moral problem here can be explained by FI. Since it is fictional that Trevor is torturing someone, and by an application of FI, fictionally, the player is Trevor, it follows that, fictionally the player is torturing someone. If, by virtue of FI, the player is complicit in fictional acts of torture and heinous violence, this would seem to explain the special moral concern surrounding videogames.

But, once again, FI lacks the nuance necessary to explain the phenomenon here. As Patridge (2017) points out, players tend to feel responsibility for some in-game actions and not others. And, as we argue below, R\&M's view does not seem to be able to explain why players only feel responsible for some of the PC's actions. Moreover, we agree with Christopher Bartel that moral criticism of videogames can be legitimate only if we can "identify which virtual actions a player can be held accountable for" (Bartel 2015, 287). While Bartel does not explain why this is so, the reasoning is not difficult to fill in. If videogames are to be subject to special moral criticism (i.e. criticism that does not equally apply to artworks in other mediums), it is not sufficient simply to look at their content (Bartel 2015, 291). After all, a film or a novel could have the same graphically violent content as a videogame. Instead, if videogames are supposed to present a special moral problem, this is likely to be due to the player's role in generating the content. That is, the nature of videogames as interactive fictions is the source of any special moral concerns that may attach to them. We can subject a videogame to legitimate, medium-specific, moral criticism only if we can determine which aspects of the game's content are due to the player's interaction with it.

We think that Bartel sets the correct agenda. To appropriately discuss moral responsibility in videogames, we need a criterion to determine which features of the game's fiction the player can be held accountable for. Since we are focused here on games with a player-character, we can narrow this demand slightly: We need a criterion to determine which of the PC's actions the player can be held accountable for. And now

16 "NPC" stands for "Non-Player Character", so a videogame NPC is any character in the game's fiction that is not a PC (and is thus not under the player's direct control). 
we are in a position to see why FI is not sufficient to explain players' responsibility for in-game actions.

As we explained above, FI explains the appropriateness of first-person reports of ingame activity by positing that the player fictionally is the PC. Consequently, any action that PC fictionally performs is thereby also an action that the player fictionally performs. Assuming for the moment that we are responsible for all of our actions-fictional and otherwise - this implies that the player is responsible for all of the PC's fictional actions. And this is clearly false. To see this, consider that many modern videogames employ "cutscenes"; cinematic sequences that are not interactive. The player simply watches the action of the cutscene, and cannot influence it by the use of the game's controls. The PC performs many fictional actions in cutscenes or other scripted events over whose content the player has no control. And in these cases, it seems clear that the PC's fictional actions cannot be the player's fictional actions. For example, when Nathan Drake flirts with Elena Fisher in a cutscene in Uncharted (Naughty Dog, 2007), it is implausible for the player to say "I flirted with Elena", and it is implausible that the player is responsible for Drake's particular words and actions in the scene. ${ }^{17}$

To get around this difficulty, R\&M could try to avail themselves of Christopher Bartel's (2015) account of player responsibility. Bartel employs a Frankfurt-style compatibilism to argue that the player is only responsible for those of the PC's actions that the player wills. To argue for this point, Bartel observes that "many of the violent acts that players commit in video games-perhaps even most of them-are not freely chosen by the player” (Bartel 2015, 289). To make this point, Bartel notes that it is only possible to complete many games by engaging in various acts of disturbing violence. The player can only complete Grand Theft Auto IV (Rockstar Games, 2008), to use his example, if she successfully wins a brutal firefight with police in the "Three Leaf Clover" mission. Consequently, given that the player has "committed herself to completing the game", she cannot have chosen otherwise than to engage in a shootout with the police (Bartel 2015, 289). Thus, Bartel argues, whether or not the player is responsible for the PC's fictional actions in the "Three Leaf Clover" mission depends on "the extent that she identifies her sense of self with the perpetration of those actions" (Bartel 2015, 291).

And Bartel does seem to be onto something here. There does seem to be a relevant difference between a player who gleefully engages the fictional police in the most violent way possible and a player who "resigns himself” to the situation and, like Bartel,

17 The case of Uncharted is especially jarring because Drake is portrayed as affable and easy-going in cutscenes, but in gameplay, under the player's control, is portrayed as a brutal and efficient killer (depending, of course, on the player's level of skill). This is the main reason why the Uncharted games remain prime examples of "ludonarrative dissonance" (Hocking 2007). 
thinks “This isn't me shooting these officers, it is Niko Bellic” (Bartel 2015, 290). By exercising her freedom to will, the player can have "a sense of detachment from the actions that her player-character is required to commit” (Bartel 2015, 291). But does this sense of detachment absolve the player of moral responsibility for the PC's actions? Bartel thinks it does: When the player does not will the PC's actions, she "does nothing more than witness [the PC's] monstrosity” (Bartel 2015, 291). Thus, on this view, the player is not responsible for all of the PC's actions, but only those that she wills.

But recent games, such as Spec Ops: The Line, that attempt to force the player to reflect critically on the actions that she is performing in the game pose a problem for Bartel's account. By the end of Spec Ops, Captain Walker has committed numerous atrocities under the player's control. When Walker finally encounters Colonel Konrad at the end of the game, Konrad says to Captain Walker, "None of this would have happened if you had just stopped.” In this scene, it is clear that Konrad is speaking not only to Walker, but to the player as well. ${ }^{18}$ None of the horrible things Walker does over the course of the game would have happened in the game's fiction-in that playing of that game-if the player had stopped playing. ${ }^{19}$ Spec Ops effectively forces players to reflect on their own complicity in fictional violence, both in Spec Ops and in other games in the "military shooter" genre, such as Call of Duty (Activision, 2003).

However, if Bartel's account were correct, the player could simply disavow Walker's actions as only being his actions, and thus absolve herself of any responsibility for the atrocities that Walker commits. But-and emphasizing this point is one of Spec Ops' central aims-Walker's actions issue from the player's interaction. And we think this is a significant point from the perspective of the player. To see this, contrast the phenomenology of watching a non-interactive cutscene to actually playing the scene. It feels different. But on Bartel's view, there should be no difference: When the player chooses to imaginatively "detach" herself from the PC, the player simply watches what the PC does, which is of course precisely what the player does in watching a cutscene. But the player does not simply watch Walker commit atrocities. As we noted above, Walker's fictional actions (outside of cutscenes, of course) are counterfactually dependent on the player's real interactions with the game's controls (see the reasoning from (i) to (ii) above). Thus, Walker acts monstrously because of the player's interactions with the game's controls, and this is the case whether or not the player "identifies her sense of self with the perpetration of those actions" (Bartel 2015, 291). In other words, Colonel Konrad has it exactly right: None of this would have happened if the player had just stopped. Thus, it seems that the player bears responsibility for those

18 See (Payne 2014) for detailed analysis of this scene and others that directly call the player to account for her role in the game's fictional violence.

19 Indeed, Walt Williams, the lead writer of Spec Ops, conceived of one possible ending to the game as the player's simply quitting in disgust at being complicit in the fictional atrocities in the game (Garland 2012). 
actions in the game's fiction that result from her interactions with the game's controls, whether or not she imaginatively identifies herself with the PC who performs those fictional actions.

We conclude that FI does not explain which of the PC's actions the player is responsible for. By itself, FI implies that the player is responsible for all of the PC's actions, including those in non-interactive cutscenes over which the player has no control. We think this is implausible. Moreover, this problem cannot be avoided by supplementing FI with Bartel's account of player responsibility. Consequently, FI fails to explain why players feel responsible for some, but not all, actions of the PC. Call this the responsibility problem.

The problems raised in this section suggest to us that FI does not capture the sense in which videogames are "self-involving" and thus does not explain why videogames are SIIFs. The central problem for R\&M's view, which Suduiko also identifies, is that we need to explain how it is possible for the player to exercise agency in the game's fiction (i.e. how it is possible for the game's fiction to be interactive) without identifying the player with any particular character in the game's fiction. However, we think R\&M are correct in holding that videogames are SIIFs; they are works which, in virtue of the consumer's interaction with them, generate fictional truths about the consumer. Consequently, since fictional identity is not what makes such works self-involving, we must develop another way to describe the relationship between the player and the player character. In the next section, we develop our alternative view, according to which the PC should be understood as the player's fictional proxy.

\section{Player-Character as Fictional Proxy}

Grant Tavinor claims that the relationship between the player and the PC is one of identity, but he also writes that the PC "is the player's fictional proxy in the world of the game" (Tavinor 2009, 74). Indeed, the idea that the PC is the player's proxy is quite common in the literature; see, for example, (Velleman 2008; Baker 2012; Klevjer 2012; Van de Mosselaer 2018). But none of those authors provide an account of the meaning of this phrase. We propose that explaining what it means to say that the PC is the player's "fictional proxy" - and how this relation differs from fictional identity-will allow us to make progress where FI falters.

To develop our account of the fictional proxy relation, we employ James MacPherson's (2010) account of proxy agency. On MacPherson's view, a proxy agent (or just proxy) acts on behalf of another party, the authorizer. MacPherson helpfully distinguishes between acting in behalf of and on behalf of. A acts in behalf of B when $\mathrm{A}$ acts so as to benefit B. By contrast, A acts on behalf of B when A's actions count as B's actions (MacPherson 2010, 11). We are interested only in the latter concept here, and we will argue that the PC is the player's fictional proxy because there is a sense in which 
the PC acts on behalf of the player, and therefore that the PC's actions count as the player's actions. But what does it mean to say that the proxy's actions count as actions of the authorizer? To explain this, MacPherson turns to the work of Thomas Hobbes. Hobbes writes:

When [the words or actions of a person] are considered as his own, then he is called a natural person: and when they are considered as representing the words or actions of another, then he is a feigned or artificial person. ${ }^{20}$

Consequently, on Hobbes' view, a proxy acting qua proxy acts as an "artificial person”. And, Hobbes continues, artificial persons

have their words and actions owned by those whom they represent. And then the person is the actor; and he that owneth his words and actions is the AUTHOR: in which case the actor acteth by authority.

Thus, for Hobbes, the words and actions of a proxy agent are "owned by" the author of those actions; viz., the authorizer whom the proxy represents. The thought is that when a proxy agent acts by my authority, I am the owner of those actions; my proxy's actions count as my actions. Notably, when this proxy relation obtains, we describe the actions of the proxy as the actions of the authorizer. For example, when I employ a proxy to bid on my behalf at an auction, we say that $I$ bid at the auction. ${ }^{21}$

Moreover, on Hobbes' view, ownership of the actions of another-as when the authorizer owns the actions of her proxy-entails responsibility for the consequences of those actions. Hobbes writes:

When the actor maketh a covenant by authority, he bindeth thereby the author, no less than if he made it himself; and no less subjecteth him to all the consequences of the same.

Thus, when my proxy bids on my behalf, $I$ am subject to the consequences of his actions; I am committed to paying the amount agreed upon, and entitled to receive the item on which my proxy bid.

Armed with MacPherson's conception of a proxy agent, we can now articulate what it means to say that the PC is the player's fictional proxy.

Fictional Proxy (FP): When the player authorizes the PC to perform a fictional action, the PC's fictional action counts as the player's fictional action.

We should clear up two initial issues about this account before proceeding further. First, the player authorizes the PC by giving input to the game; typically, by pressing a button on the game's controller. Recall our earlier example:

20 All quotations of Hobbes are from Leviathan, Book I, Ch. XVI, and are quoted in (MacPherson 2010).

21 This example is MacPherson's. 
(i) Really, I pressed the X button on my gamepad,

and as a result,

(ii) fictionally, Captain Walker took cover behind a barricade.

We can now observe that the relationship between (i) and (ii) exemplifies the fictional proxy relation. Captain Walker's fictional act is authorized by my real act of pressing X on the controller. In general, the player's interaction with the game's controls is the means by which the player authorizes the PC's actions. ${ }^{22}$

But this raises a second important issue. What we have said so far is that the player authorizes the PC to perform a fictional action by providing input to the game. But because the fiction is interactive in the way exemplified by the relation between (i) and (ii), this really means that the player causes the PC to perform a fictional action. That is, the relationship between (i) and (ii) is ultimately a causal relationship, and this seems to be importantly different from a relationship of authorization. In typical real-world cases involving a proxy agent, an authorizer does not cause their proxy to perform an action on their behalf, and this is in part because, in typical cases, this proxy is an agent in their own right. By contrast, the PC of a videogame is not really an agent. Nevertheless, in most cases the PC is fictionally an agent. ${ }^{23}$ So it cannot be the case that the player merely causes the PC's fictional actions, as that would make the PC simply an instrument of the player in game's fiction. ${ }^{24}$ We thus employ the term "fictional proxy" in part to preserve the sense of the PC's fictional agency. On our view, an important way in which a fictional proxy differs from a real proxy is that the player authorizes the fictional proxy's actions by causing them via her interactions with the game's controls. Thus, when Captain Walker takes cover because the player presses the $\mathrm{X}$ button, Walker's action is authorized by the player.

22 Moreover, we suspect, the button mapping (or key-binding) scheme of a game generally functions to determine which fictional actions can be authorized in the game, and thus determine the ways in which it is possible to interact with the game's fiction. No matter how much one might like to comfort Elizabeth by hugging her in BioShock Infinite (Irrational Games, 2013), this is simply not possible because "hug" is not mapped to a button or keypress. We also find it noteworthy that buttons/keys are nearly always mapped to diegetic actions — run, jump, shoot—as opposed to other features of the PC’s situation (e.g. being angry). For detailed and helpful discussion of the relationship between control schemes and virtual actions, see (Gregersen and Grodal 2008).

23 It's important to emphasize here that the PC is fictionally an agent distinct from the player. For more on this point, see Suduiko's helpful discussion of the "epistemic datum” in (Suduiko 2018, 9).

24 There are unusual cases in which it is part of the game's fiction that the PC is merely an instrument, and not even an agent in the game's fiction. BioShock (2K Games, 2007) is a noteworthy example here. But cases like this are noteworthy in part because they are so unusual. In more standard cases, as Felix Schröter (2016) argues, it seems plausible that players may shift between thinking of the PC as a character and thinking of the PC as a tool. As Schröter puts it: "While playing Tomb Raider (Crystal Dynamics and Eidos Montreal, 2013), I may be seeing Lara primarily as a tool, which allows me to overcome the obstacles the game confronts me with, but I can still, at times, feel pity for Lara as she suffers from injuries or mourns the death of one of her companions" (Schröter 2016, 38-39). 
With these clarifications in place, we are now in a position to show how FP solves the problems that, we argued, FI does not solve. First, let's consider how it explains the appropriateness of first-person descriptions of in-game action. Consider once again our main example:

(i) Really, I pressed the X button on my gamepad,

and as a result,

(ii) fictionally, Captain Walker took cover behind a barricade.

As we explained above, the relationship between (i) and (ii) shows that Walker's fictional action is authorized by the player. Thus, applying FP, we have that Captain Walker's fictional action counts as the player's fictional action; Captain Walker's taking cover behind a barricade counts as my taking cover behind a barricade. And, as noted above, when this "counts as" relation obtains, we simply describe the actions of the proxy as the actions of the authorizer. Thus, we have

(iii) fictionally, I took cover behind a barricade.

Consequently, FP readily explains why first-person descriptions of in-game action are appropriate. Moreover, while our proxy's actions count as our actions, we do not generally share other features of our proxy's situation. When my proxy bids on my behalf at the auction, we say that $I$ bid at the auction. But if my proxy was feeling irritated when he bid, we don't say that $I$ was feeling irritated when I bid. And FP accords with this observation. FP only says that the PC's actions count as the player's. Consequently, the inference from

(ii*) fictionally, Walker is angry at the refugees in Dubai,

to

(iii*) fictionally, I am angry at the refugees in Dubai,

which is licensed by FI, is not licensed by FP. Thus, we contend, FP avoids the asymmetry problem.

Moreover, the fictional proxy account developed here might help to explain how the player is related to the fictional player that Suduiko posits. As we noted in our discussion of Suduiko's view, the relationship between the fictional player's actions and the player's actions is in need of explanation. Our fictional proxy account might help in this regard. Especially in cases of games without a single PC (as Suduiko's variability datum highlights), it might make sense to posit a fictional player as the player's fictional proxy. The thought here is that the fictional proxy view can explain how in-game actions can count as the player's actions, even if they are not the actions of a character in the game's fiction. In games with a single PC, the PC is, as it were, the location of the player's power to act in the game's fiction. But, we propose, the player's power to act 
need not be so located. The player's proxy could be a gust of wind, as in Flower (Thatgamecompany, 2009), or multiple characters simultaneously, as in Brothers: A Tale of Two Sons (Starbreeze Studios, 2013), or perhaps even something like Suduiko's fictional player. ${ }^{25}$ The latter might be especially helpful in explaining how the player authorizes actions in games like Sim City (Maxis, 1989), in which no character provided by the game's fiction seems to serve as the player's proxy. In such cases, the most promising account might be that, e.g., the player authorizes the fictional building of a hospital in Sim City by authorizing a fictional player to act. ${ }^{26}$ We lack the space to pursue these suggestions further here, but we think that investigating the possible variability of fictional proxies is a promising avenue for future research.

Finally, FP solves the responsibility problem. As we pointed out above, some recent games like Spec Ops: The Line offer a compelling look at moral responsibility in videogames, but FI cannot help us to determine which of the PC's actions the player can be responsible for, and thus cannot account for the special questions of moral responsibility that videogames raise. However, FP does not have this consequence. According to FP, when the PC's actions are authorized by the player, they belong to the player, and that includes the consequences of those actions. Thus, the player cannot simply disavow the PC's actions by refusing to imagine herself to be identical with the PC. Since the PC's actions in the game's fiction occur only because they were authorized by the player (via the player's input with the game's controls), the player owns the PC's actions, and their consequences. Thus Konrad, in addressing both Captain Walker and the player, has it exactly right: You - the player-are responsible for what happened in the game's fiction, because "none of this would have happened if you had just stopped." By contrast, FP does not imply player responsibility for PC actions that are not authorized (say, actions that occur in cutscenes). FP thus meets Bartel's challenge to explain which actions of the PC the player should be held accountable for. For, FP implies that the player should be held accountable for just those actions of the PC that she authorized. FP thus allows for the emotional power and clever critique presented in games like Spec Ops: The Line and Hotline Miami (Dennaton Games, 2012), both of which are designed to directly confront the player about the immoral actions they commit over the course of the game. FP allows us to make sense of the impact of these critiques while FI cannot.

Let us take stock. As we noted above, we agree with Robson and Meskin in holding that videogames are works of self-involving interactive fiction. But, on our view, what

25 See (Baker 2012, 37) for interesting further suggestions germane to this point.

26 In the case of Sim City, it might be argued that there is a character in the game's fiction who is supposed to serve as the player's proxy; namely, the mayor of the city. But given that it is possible to summon monsters and natural disasters in Sim City, this is implausible. For this and similar reasons Grant Tavinor concludes that "the description of the player as a mayor... seems inconsistent with the fiction of the game.” (Tavinor 2009, 73) 
makes them self-involving is the particular way in which they are interactive: A videogame is self-involving when and to the extent that a player interacts with it by authorizing in-game actions of a fictional proxy by use of the game's controls. Our fictional proxy account pays special attention to the unique way in which videogames are interactive and thereby makes sense of the way in which players talk about their gameplay experiences, and of the sense of moral responsibility that gameplay can engender.

\section{Games}

2K Games (2007). BioShock.

Activision (2003). Call of Duty.

Bantam Books (1979-1998). Choose Your Own Adventure.

Capcom (2009). Resident Evil 5.

Crystal Dynamics and Eidos Montreal (2013). Tomb Raider.

Dennaton Games (2012). Hotline Miami.

Galactic Cafe (2013). The Stanley Parable.

id Software (2016). Doom.

Irrational Games (2013). BioShock Infinite.

Maxis (1989). Sim City.

Naughty Dog (2007). Uncharted.

Rockstar Games (2008). Grand Theft Auto IV.

Rockstar Games (2013). Grand Theft Auto V.

Starbreeze Studios (2013). Brothers: A Tale of Two Sons.

Tactical Studies Rules, Inc. (1974). Dungeons \& Dragons.

Thatgamecompany (2009). Flower.

Yager Development (2012). Spec Ops: The Line.

\section{References}

Baker, A. (2012). Videogames as Representational Art. Postgraduate Journal of Aesthetics, 9(2), 2839.

Bartel, C. (2015). Free will and moral responsibility in video games. Ethics and Information Technology, 17, 285-293.

Carroll, N. (1990). The Philosophy of Horror. Routledge.

Carroll, N. (2001). Simulation, Emotions, and Morality. In Beyond Aesthetics: Philosophical Essays. Cambridge University Press, 306-316.

Conrad, J. (1899). Heart of Darkness. Blackwood’s Edinburgh Magazine, February—April.

Garland, J. (2012). Aftermath: crossing The Line with Walt Williams. GamingBolt. Accessed on 3/27/2019. http://gamingbolt.com/aftermath-crossing-the-line-with-walt-williams

Gaut, B. (1999). Identification and Emotion in Narrative Film. In Passionate Views. The Johns Hopkins University Press, 200-216.

Gregersen, A. and Grodal, T. (2008). Embodiment and Interface. In The Video Game Theory Reader 2, Edited by Bernard Perron and Mark J.P. Wolf. Routledge, 65-83. 
Hocking, C. (2007). Ludonarrative Dissonance in Bioshock. Click Nothing. Accessed on 3/27/2019. http://clicknothing.typepad.com/click_nothing/2007/10/ludonarrative-d.html

Juul, J. (2005). Half-Real: Video Games between Real Rules and Fictional Worlds. MIT Press.

Klevjer, R. (2012). Enter the Avatar. The phenomenology of prosthetic telepresence in computer games. In The Philosophy of Computer Games, Edited by Hallvard Fossheim, Tarjei Mandt Larsen, and John Richard Sageng. Springer, 17-38.

Lopes, D. (2010). A Philosophy of Computer Art. Routledge.

MacPherson, J. (2010). Legislative Intentionalism and Proxy Agency. Law and Philosophy, 29, 1-29.

Patridge, S. (2017). Video Games and Imaginative Identification. The Journal of Aesthetics and Art Criticism, 75(2), 181-184.

Payne, M. (2014). War Bytes: The Critique of Militainment in Spec Ops: The Line. Critical Studies in Media Communication, 31(4), 265-282.

Robson, J. and Meskin, A. (2016). Video Games as Self-Involving Interactive Fictions. The Journal of Aesthetics and Art Criticism, 74(2), 165-177.

Robson, J. and Meskin, A. (2017). Still Self-Involved: A Reply to Patridge. The Journal of Aesthetics and Art Criticism, 75(2), 184-187.

Schröter, F. (2016). My Avatar and Me: Toward a Cognitive Theory of Video Game Characters. In Video Games and the Mind, Edited by Bernard Perron and Felix Schröter. McFarland \& Company, 32-52.

Suduiko, A. (2018). The Role of the Player in Interactive Fictions. Journal of the Philosophy of Games, 1(1), 1-17.

Tavinor, G. (2009). The Art of Videogames. Wiley-Blackwell.

Van de Mosselaer, N. (2018). Fictionally Flipping Tetrominoes? Defining the Fictionality of a Videogame Player's Actions. Journal of the Philosophy of Games, 1(1), 1-12.

Velleman, J. D. (2008). Bodies, Selves. American Imago, 65(3), 405-426.

Walton, K. (1990). Mimesis as Make-Believe: On the Foundations of the Representational Arts. Harvard University Press.

Wollheim, R. (1973). Imagination and Identification. In On Art and The Mind. Allen Lane, 54-83. 